\title{
FORÇA RELATIVA DA ETNICIDADE ENTRE OS JOVENS NIPO-BRASILEIROS NA CIDADE DE SÃO PAULO
}

\author{
Maria Juliana Konigame ${ }^{1}$
}

\begin{abstract}
Resumo: Após mais de cem anos de imigração japonesa para o Brasil, diversas pesquisas exploraram largamente as primeiras gerações de japoneses e seus descendentes no Brasil; a presente pesquisa pretendeu analisar as gerações mais novas de descendentes de japoneses na cidade de São Paulo, buscando explorar questões mais recentes que surgem dentro da comunidade étnica. À medida que as gerações mais novas vão se afastando das primeiras gerações de imigrantes observarmos algumas mudanças na dinâmica da comunidade étnica. A fim de compreender essas mudanças, focamos a análise na problemática da retenção da etnicidade por parte das gerações mais novas. Para tanto, a pesquisa procurou observar a formação de identidades étnicas entre os jovens nipo-brasileiros através da análise do envolvimento desses jovens com associações étnicas. Entre os resultados desse estudo observamos que há uma tendência entre os jovens descendentes de japoneses em construir uma noção de etnicidade por meio da proximidade ou distância de associações ou agrupamentos étnicos que pode variar bastante de acordo com o período da vida em que se encontram. Também pudemos observar que há variados modos de participar na comunidade de acordo com a faixa etária, local de moradia etc. De modo geral, a persistência da etnicidade entre as gerações mais novas se mostra essencial nas discussões sobre o futuro das associações étnicas e a manutenção da comunidade de nipo-brasileiros. Enquanto houver aparatos comunitários, associações ativas e voluntários jovens que deem continuidade a todo esse aparato, a percepção da existência de uma relativamente forte e visível comunidade nipo-brasileira (marcada por essas instituições espalhadas por toda cidade de São Paulo) irá persistir.
\end{abstract}

Palavras-chave: comunidade étnica; etnicidade, associações nipo-brasileiras, jovens.

Abstract: After over one hundred years of Japanese immigration to Brazil, several studies largely explored the first generations of Japanese and their descendants in Brazil; this article analyzes the younger generations of Japanese descendants in São Paulo city, exploring more recent issues that arise within the ethnic community. As the younger generations move away from the first generations of immigrants some changes were observed in the dynamics of the ethnic community. In order to understand these changes, we focus the analysis on the problem of ethnicity retention by the younger generations. Therefore, the research sought to observe the formation of ethnic identities among Japanese-Brazilian youth by examining the involvement of these young people with ethnic associations. Among the results of this study was observed that there is a tendency among young people of Japanese descent in building a sense of ethnicity by proximity or distance of associations or ethnic groups which can vary greatly depending on the period of life. We could also note that there are

Mestre em Sociologia pela Universidade de São Paulo (USP), bolsista da Coordenação de Aperfeiçoamento de Pessoal de Nível Superior (CAPES). Doutoranda pela Universidade de Tsukuba, bolsista do Monbukagakusho (MEXT). 


\begin{abstract}
various ways to participate in the community according to age, place of residence etc. Overall, the persistence of ethnicity among the younger generations seems to be essential in discussions on the future of Japanese-Brazilian ethnic associations. While there are community apparatus, active associations and youth volunteers that give continuity to all this apparatus, the perception of exist a relatively strong and visible Japanese-Brazilian community (marked by these institutions spread throughout the city of São Paulo) will persist.
\end{abstract}

Key-words: ethnic community; ethnicity, Japanese-Brazilian associations, young population.

\title{
OS ESTUDOS SOBRE JAPONESES E DESCENDENTES EM SÃO PAULO
}

Os estudos sobre a comunidade nipo-brasileira nas ciências sociais não são novos, entre os estudos mais relevantes encontra-se o de Ruth Cardoso. Em sua tese de doutorado de 1972 sobre os japoneses no estado de São Paulo, Cardoso analisou a mobilidade social desse grupo étnico e seus descendentes no Brasil.

A autora procurou mostrar, a partir de diversas pesquisas, o modo de integração dos japoneses em São Paulo primeiramente por meio do trabalho assalariado dos issei ${ }^{2}$, depois quando estes passam a serem proprietários urbanos em busca de melhor educação para os seus filhos e, por fim, através da tentativa de mobilidade social dos nissei, com o intuito de se consolidarem como profissionais liberais no mercado de trabalho brasileiro. Para tanto, as questões étnicas e identitárias são colocadas em questão, à medida que o sucesso e a integração socioeconômica dependem de um maior diálogo e abertura com a população brasileira em geral.

A partir desses estudos, procuramos analisar novas questões relacionadas aos nipo-brasileiros, dessa vez com enfoque nos jovens (ou seja, nas gerações mais novas de descendentes de japoneses nascidos no Brasil), na cidade de São Paulo.

Partindo da ideia de que a identidade nipo-brasileira permite a existência de uma dupla identidade étnica, cada uma com uma força relativa que varia de acordo com o contexto (podendo-se enfatizar ora uma, ora outra), e seguindo a ideia de Seyferth (2005: 21) de que: "as identidades com hífen, que remetem a um duplo pertencimento, são [...] exemplo de conciliação de categorias múltiplas de identificação", pretendeu-se observar a força relativa da etnicidade entre os jovens descendentes de japoneses dentro desse contexto de identidades múltiplas.

Issei, Nissei, Sansei e Yonsei são termos normalmente utilizados para se referir respectivamente à $1^{\circ}$ geração (formada por imigrantes de japoneses) e $2^{\circ}, 3^{\circ} \mathrm{e} 4^{\circ}$ gerações (formadas por descendentes nascidos fora do Japão, ou seja, respectivamente, filhos, netos e bisnetos de japoneses). 
Também fez parte do escopo dessa pesquisa compreender quais novas questões se colocam para as gerações mais novas de descendentes de japoneses, tendo em vista que essas gerações tendem a se diferenciar das gerações mais antigas. Tais diferenciações podem ser observadas em relação às diferentes questões identitárias pelas quais as gerações mais novas passam à medida que vão se afastando das primeiras gerações de imigrantes e, de maneira mais ampla, à medida que vão surgindo novos acontecimentos (sociais, políticos, econômicos e culturais) que vão afetando a comunidade nipo-brasileira como um todo. A própria dinâmica interna da comunidade nipo-brasileira tende a se alterar, à medida que os mais jovens vão adentrando e liderando as associações nipo-brasileiras, impondo assim, suas próprias características, atitudes e pensamento à comunidade étnica em geral.

\section{FORÇA RELATIVA DA ETNICIDADE ENTRE OS JOVENS NIPO-BRASILEIROS}

A fim de analisar a força da etnicidade entre os jovens nipo-brasileiros, a pesquisa procurou observar qual a relação que se forma entre os jovens nipo-brasileiros e suas identidades étnicas através da análise do envolvimento desses jovens com associações nipo-brasileiras, isto é, sua capacidade de reter relativamente altos níveis de envolvimento com associações e atividades relacionadas à comunidade étnica.

A problemática da persistência da etnicidade por parte das gerações mais novas mostra-se relevante para a manutenção da comunidade nipobrasileira em geral. Além disso, os nipo-brasileiros (principalmente os que possuem fenótipo oriental) tendem a ser julgados pela sua proximidade às características étnicas; porém, se estes não se identificam, não se interessam ou não se socializam com o grupo étnico, isso poderia ser uma prova do enfraquecimento da etnicidade.

De modo geral, as relações entre o lado étnico (nipônico) e a identidade nacional brasileira, assim como as diferenciações entre gerações mais antigas e mais novas, fazem parte do que a pesquisadora Giralda Seyferth intitula de "identidades múltiplas". Segundo ela:

A noção de identidades múltiplas (...) remete à heterogeneidade, à diferenciação interna marcada por clivagens regionais, religiosas, de classe, geracionais etc. $\mathrm{O}$ exemplo dos imigrantes japoneses e seus descendentes no Brasil é demonstrativo dessa dinâmica classificatória. A categoria étnica mais geral - japonês - é construída internamente por oposição aos outros, ancoradas em distinções culturais. Mas 
existem outras categorias, assinaladas pelos estudiosos dessa imigração (...), assinalando diferenças culturais e fenotípicas; ou que estão referidas às diferentes gerações que também operam com critérios de menos ou maior aproximação com a sociedade brasileira. (SEYFERTH, 2005: 22)

Agindo como uma força de diferenciação interna à comunidade nipobrasileira, as gerações mais novas são vistas como os responsáveis pelo futuro da comunidade (e de sua imagem), de modo que a maneira como essas irão manter a etnicidade é crucial, principalmente em relação à manutenção de associações étnicas, por exemplo.

Assim, como iremos observar a relação entre - comunidade nipobrasileira, os jovens e a identidade étnica - ocorre por via da noção de aproximação com a "colônia japonesa" (como muitos entrevistados apontam), ou seja, da proximidade ou distância dos agrupamentos étnicos. A questão terminológica aqui se mostra fundamental a fim de se observar as diferenças feitas na prática dentro da comunidade: nas falas dos entrevistados, aqueles mais próximos da comunidade, são intitulados como "japoneses de colônia" (um dos possíveis termos para se referir ao nipo-brasileiro que mantém fortes relações com o grupo étnico), enquanto que os demais são vistos como "japoneses normais".

O ponto principal é que quanto maior o interesse pela comunidade, e participação ativa em associações, eventos, cursos étnicos (de língua, esportivos, artísticos etc.), maior seria a retenção da etnicidade e manutenção da comunidade entre as gerações mais novas, e, portanto, a força e permanência dos estereótipos grupais. De acordo com Gans (1979: 8):

\footnotetext{
A terceira geração pode participar de uma organização étnica, ou tomar parte em organizações formais ou informais composta largamente de companheiros étnicos; mas eles também podem encontrar suas identidades pela 'afiliação' com um coletivo abstrato que não existe como um grupo interativo. Coletividade que, além disso, pode ser mítica ou real, contemporânea ou histórica (tradução e grifos nossos).
}

Assim, apesar da tendência da maioria da população nipo-brasileira (em especial as gerações mais novas), em se afastar das associações e atividades étnicas, para que a comunidade possa continuar tendo força como agrupamento étnico distinto é preciso mais do que apenas um envolvimento psicológico ou simbólico e abstrato ${ }^{3}$; é preciso existir de fato -

\footnotetext{
Visto que a comunidade simbólica, imaginada, abrange a todos de forma mais ou menos igual, ou seja, independente da participação
} nas associações e agrupamentos étnicos. 
ou de forma concreta - associações, eventos, cursos, ainda ativos atualmente (não esvaziados de jovens e crianças), com forte público formado por membros étnicos que possam manter todo aparato étnico existente "ainda vivo".

Fugita e O'Brien (1991: 4) pesquisando a persistência da etnicidade entre as gerações mais novas de nipo-americanos, afirmam que:

\footnotetext{
A maioria dos nipo-americanos vive em vizinhanças predominantemente caucasianas, possuem amigos caucasianos, participam em assuntos da comunidade principal, e começaram a ter casamentos interétnicos em número significativo com os americanos caucasianos. [...] Contudo, nossos dados irão mostrar que, comparados com a maioria dos membros de grupos étnicos de segunda e terceira geração, em estágios similares de assimilação estrutural, os nipo-americanos têm retido um nível muito alto de participação em associações voluntárias étnicas e outras formas de comportamento, ao invés do mero envolvimento psicológico na vida da comunidade étnica (tradução e grifos nossos).
}

Seguindo essa linha de raciocínio buscamos observar (mais do que um mero envolvimento psicológico ou simbólico com a comunidade) as formas de interação e participação ativa dos jovens dentro da comunidade.

\section{MODO COMO AS GERAÇÕES MAIS NOVAS DE NIPO-BRASILEIROS "DESCOBREM A COMUNIDADE"}

Uma vez que existem, na cidade de São Paulo, muitas associações de bairro, clubes, escola de língua, cultura ou esporte japonês, de algum modo o jovem nipo-brasileiro acaba tendo seus primeiros contatos com a "comunidade nipo-brasileira" já na infância. Porém, no caso dos nossos entrevistados, foi na adolescência que o interesse se tornou maior e mais genuíno, sem a influência direta dos pais, avós e outros membros da família sobre a sua socialização.

Apesar de a identidade étnica poder ser formada em vários estágios da vida e não particularmente em apenas um, é na adolescência que muito dos conflitos e conscientizações se tornam mais claros. Enfocaremos, portanto, mais esse período da adolescência, com a entrada e socialização dentro do grupo étnico, assim como sua dispersão e posterior "saída" do grupo, no começo da vida adulta.

Dentro desse contexto, por mais que os pais incentivem os filhos a frequentar algum curso relacionado à cultura japonesa, ou que a família frequente algum clube, associação, ou instituições religiosas voltadas aos 
nipo-brasileiros, nem sempre o interesse pela cultura ou comunidade aflora na infância, ou é feito de forma espontânea (de vontade própria, interesse genuíno) pela criança. No entanto, é desses primeiros contatos que começam a surgir suas noções de "comunidade nipo-brasileira" ou identidade étnica.

Esse é o caso de vários entrevistados que relataram suas experiências de contato com a cultura nipo-brasileira, ou - utilizando as palavras dos meus próprios entrevistados - no modo como "descobriram a comunidade". Muitos tiveram fraco contato ou interesse na infância, influenciados majoritariamente pelos pais ou avós e seus locais de socialização; porém, mais tarde, na adolescência, passam a ser influenciados mais pelos irmãos, primos e amigos que formam uma rede social de vínculos mais fortes, de modo a tornar mais genuíno o seu interesse (ou não) pela comunidade étnica nipo-brasileira.

Assim, nos relatos abaixo é possível observar as noções, estereótipos e pré-julgamentos que esses jovens aprenderam a fazer durante a infância sobre o que seria a comunidade nipo-brasileira, antes de conhecê-la melhor, na adolescência. Suas visões em relação à comunidade vão se modificando na medida em que o contato se torna maior, seus estranhamentos iniciais vão se transformando, e suas opiniões sobre suas próprias identidades étnicas começam a ser estabelecidas.

\section{INFÂNCIA}

São comuns os relatos de que, já na infância, os jovens nipo-brasileiros da cidade de São Paulo começam a ter algum contato com aspectos da comunidade nipo-brasileira, seja de forma puramente simbólica (no que ouvem falar sobre o grupo étnico, na manipulação da simbologia étnica, seja por parte de membros do grupo étnico ou por pessoas de fora do grupo) ou de maneira mais prática (frequentando espaços ou atividades étnicas).

No caso de Vinícius ${ }^{4}$, jovem de 24 anos, ele afirma que seus avós eram não só grandes frequentadores de um kaikan ${ }^{5}$ da Zona Norte, como também ocupavam uma posição alta dentro da associação. Assim, seus avós participavam semanalmente dos eventos da associação, especialmente dos encontros de karaokê e de dança (voltados mais à terceira idade).

\footnotetext{
Os nomes de todos os entrevistados foram alterados.

No Brasil kaikan é um tipo de associação de caráter cultural e esportivo que procura manter tradições da cultura japonesa.
} 
Vinícius, juntamente com seu irmão, era levado ao kaikan pela avó, e enquanto esta fazia suas atividades, eles costumavam jogar futebol, porém ele não se interessava muito pela associação, pois não se socializava muito com os outros meninos, que "eram muito panelinha", chegando até a brigar com umas pessoas de lá. Seu interesse por pessoas do mesmo grupo étnico só veio mesmo posteriormente, na época do colegial, quando mudou de casa (aos 16 anos) e passou a morar num bairro da zona sul da cidade de São Paulo, onde passou a ter mais contato com jovens nipo-brasileiros da sua idade.

Já no caso de Luís (21 anos), este relatou que na infância - mais especificamente quando estava na antiga $4^{\circ}$ série do ensino fundamental (aos dez anos de idade) - estudava nihongo (língua japonesa), lembrando que a professora (que não falava muito bem o português) tentava influenciá-lo e queria que ele participasse de undokai (festividade esportiva tradicional da sociedade japonesa), e tentando ainda fazê-lo interessar-se por mangá etc.

Posteriormente, ele tentou frequentar um kaikan da zona leste da cidade de São Paulo, mas na época não tinha jovens da sua idade. Nessa associação só havia um grupo de senhores que gostavam de karaokê. Além disso, como estudou a maior parte da sua infância e adolescência em escolas públicas nas quais não tinham muitos nipo-brasileiros (só na $8^{\circ}$ série mudou para uma escola particular que tinha mais nipo-brasileiros), acabou não tendo muito contato com outros descendentes de japoneses além de seus primos.

De acordo com Luís, que já havia frequentado curso de língua japonesa na infância e conhecia um kaikan do bairro perto de onde morava, "foi só no $1^{\circ}$ ano de colegial que comecei a entrar nesse mundo [dos nipobrasileiros]". Depois ele acaba se socializando mais com brasileiros não descendentes de japonês e afirma "isso foi o mais próximo da cultura japonesa que cheguei".

É interessante notar aqui a noção de "começar a entrar nesse mundo", e "foi o mais próximo que cheguei". Esses tipos de falas aparecem muito nos discursos dos jovens nipo-brasileiros. A comunidade étnica, portanto, é muitas vezes entendida como algo da qual em alguns momentos se faz parte e em outros não. A noção de "entrar e sair" do grupo étnico se mostra forte, confirmando essa ideia.

Por fim, Fernando afirma que frequentava eventos relacionados a karaokê, pois o pai era músico, então cresceu nesse meio da música. Chegou a frequentar kaikan e o $B_{u n k y o}{ }^{6}$, mas não era nada que ele levasse a

OBunkyo é um dos órgãos centrais entre todas as outras entidades nipo-brasileiras no Brasil e, segundo informações do seu site, tem a missão de "representar a comunidade nipo-brasileira, promover a preservação e divulgação da cultura japonesa no Brasil e 
sério, como acontecerá posteriormente, no fim da adolescência, já aos vinte anos, quando começa a frequentar o Bunkyo mais seriamente.

Assim, como pudemos observar, os contatos na infância ocorrem mais por influência dos pais, avós, ou até da professora de língua japonesa, mas de modo geral, não produz fortes identificações com o grupo étnico, sendo mais uma exposição inicial ou interesse inicial do que uma identificação mais profunda (em relação a estes casos apresentados). Como veremos adiante, é na adolescência até o período de faculdade que a identidade étnica vai tomando uma forma mais clara.

\section{SOCIALIZAÇÃO (FORMAÇÃO DE IDENTIDADE E SÍMBOLOS ÉTNICOS)}

Apesar de todos os entrevistados já terem sido expostos às associações e grupos étnicos na infância, é interessante notar em suas falas o modo como afirmam ter tido contato com o grupo étnico, enfatizado o período da adolescência.

Assim, no caso de Vinícius, apesar de já ter participado algumas vezes de kaikans quando era mais novo, naquela época ele não havia se enturmado muito com os demais meninos, já na adolescência, o aspecto da socialização se mostrou muito importante para manter o contato com o grupo étnico. Ele afirma que "só no colegial que eu fui ter amigos de verdade, antes disso não", ou seja, no caso de Vinícius a procura por membros do grupo étnico serviu como forma de criar vínculos fortes de amizade que ele não encontrava anteriormente. $\mathrm{O}$ caso desse jovem mostra que, em algumas situações, os laços fortes de amizade tendem a ocorrer de forma mais natural entre os membros do mesmo grupo étnico, do que entre os que não são do mesmo grupo. Isso pode ser um indicativo de que a etnicidade ainda é forte entre as gerações mais novas de nipo-brasileiros.

De acordo com a trajetória de Vinícius, vemos que ele havia estudado na infância em um colégio municipal da Zona Norte, onde morava (no qual não teve muito contato com outros descendentes de japoneses, nem na escola, nem em seus locais de socialização fora da escola). Depois mudou de bairro e foi estudar no Colégio São Luís, entre a $7^{\circ}$ e $8^{\circ}$ séries do antigo ensino fundamental. Porém, de acordo com ele: "odiava lá, só tinha patricinha e mauricinho".

da brasileira no Japão, e apoiar as iniciativas voltadas a essa finalidade". http://www.bunkyo.bunkyonet.org.br/index.php Acessado em 06/2010. 
Ele afirma: "contato com colônia só no colegial", que foi quando ele entrou no curso de ensino médio de um colégio federal. Foi no último ano desse colégio que ele "conheceu os japoneses" (expressão usada por ele).

Em suas falas, ele afirma: "quando entrei no kaikan (da Zona Sul, próxima a onde morava) foi quando comecei a ter amigos de verdade. Contato com a colônia eu comecei a ter no colegial mesmo; no terceiro colegial eu conheci os 'japas', aí entrei para colônia”.

As noções de "contatos com a colônia" e "entrar para a colônia" são fortes indicações de como a etnicidade não está naturalizada, sendo, portanto, algo que precisa ser construído por eles em suas trajetórias individuais para existir ou aflorar com mais clareza.

De modo geral, a identidade étnica é uma formação dentro da identidade mais ampla que é ser brasileiro. Veremos, por exemplo, que toda a noção do que seja "ser japonês" ou ser étnico na fala dos entrevistados, é uma formação em cima da primeira noção que eles possuem de identidade, que é a identidade nacional, ou seja, o "estereótipo" do que é ser japonês é formado em relação às diferenças apresentadas no que se espera de um "brasileiro" normal, ou como este se comportaria.

Uma das primeiras características para se definir o pertencimento a um grupo étnico é a socialização relativamente forte com os membros desse grupo, de modo que, quando perguntado sobre o que era colônia (japonesa), termo recorrente nas falas dos entrevistados, Vinícius responde: "é os caras que só andavam com japa assim, aí eu falei: nossa porque vocês só andam com japa? aí eu comecei a andar com japa também. Estou até hoje assim. Não... na verdade eu tenho amigos não japas, mas eu tenho mais familiaridade com japa" (de novo, os laços fortes com membros do grupo étnico mostram a força da etnicidade atuando sobre as gerações mais novas). Desse modo, fica implícito que, na opinião do entrevistado, para "entrar para a comunidade", ou para "ser japonês de colônia", é necessário participar de grupos onde há grande concentração de descendente de japoneses.

Sobre suas primeiras impressões ao "descobrir a colônia", ele relata:

Eu fiquei impressionado no começo: o que é isso? eu não sabia que tinha essa união né? tanto que, na Seicho No-le na época... antes disso eu ia direto na Seicho No-le, mas nos normais, assim que era para a população toda, aí depois que descobri que tinha um só para nikkeis ${ }^{7}$, a maioria era nikkei pelo menos, e aí eu fui com essa galera que eu conheci na Federal (ensino médio), tudo japa: nossa é bem mais da hora, não sei [bem explicar] por que...

\footnotetext{
Termo que serve para se referir aos membros da diáspora japonesa.
} 
Aqui podemos observar que, se antes não era natural a formação de grupos constituídos só por membros étnicos, ou seja, se quando o jovem estava "de fora da colônia" isso parecia ser estranho, desconhecido, logo depois se tornou algo natural, eram grupos de jovens da sua idade que se socializam entre si e possuíam suas próprias atividades de lazer, comportamentos, opiniões, jeito de ser etc., algo que até então era desconhecido. É como se tivesse achado um nicho de socialização "ideal", no sentido de ser formado por outros jovens com os quais possui forte identificação.

Sendo mais preciso, o encontro com esse nicho ocorreu inicialmente quando Vinicius, já morava na Zona Sul: ele foi um dia ao parque das bicicletas onde fica a pista de atletismo e conheceu o pessoal: "quando eu vi o pessoal do atletismo [que faziam parte de um kaikan] todo mundo junto naquele parque das bicicletas, eu fiquei muito curioso na verdade, eu fiquei querendo ser parte desse grupo, tanto é que eu entrei depois".

Posteriormente, acabou tendo contato também com outros jovens nipobrasileiros no colegial, quando saiu do colégio São Luís e foi estudar na escola federal. Sobre a escola federal, perguntado se onde ele estudava havia muitos orientais, Vinicius responde:

\footnotetext{
Tinha bastante, mas no primeiro e no segundo colegial eu não via esses grupinhos assim, só de japa. Tinha oriental, mas não era de colônia, talvez porque... “eram normais” assim. Aí no terceiro colegial que eu conheci uma galera que era de colônia, os caras dançavam em grupo, de street dance, mó badaladinho eles, eram os meus ídolos... oh! queria ser que nem eles. Eles sabiam fazer..., tudo ficava dança lá, e eu que era o nerdinho do grupo (grifos nossos).
}

Aqui novamente aparece a ideia de "japoneses normais", ou seja, aqueles que se comportam como qualquer brasileiro, que socializam normalmente com brasileiros a despeito da existência dos grupos étnicos.

Nesse sentido, pode-se questionar qual a diferença entre "os japoneses normais" e "aqueles de colônia". É o próprio informante quem responde: japonês de colônia "são aqueles que andavam com mochila Jansport na bunda, com cabelo $M c D o n a l d s$, bonezinho, fazia street [dance] e frequentava o Shopping Santa Cruz. Eu achava meio tapado esses moleques que faziam isso, mas eu ia no Santa Cruz e gostava também de ver..."

Essa caracterização estereotipada do "japonês de colônia" - incluindo as suas vestimentas (que se referem também a um estilo de vida) - é uma caracterização datada dos anos 2000, na época da adolescência de Vinícius. É difícil afirmar de onde surgiram essas influencias no modo de se vestir e 
de se comportar, mas o fato é que, por um tempo, dentro da cidade de São Paulo, houve a formação desses estereótipos relacionados a grupos de dança de street dance, modos de se vestir específicos e lugares de socialização privilegiados pelos nipo-brasileiros, como o Shopping Metrô Santa Cruz (localizado em uma região com relativamente grande concentração de asiáticos).

É curioso notar o estranhamento - ou talvez fosse melhor falar em incômodo - dos próprios nipo-brasileiros com o comportamento étnico, sendo interessante observar os pontos nos quais esses estranhamentos aparecem, pois não é só no início dos contatos, acontecendo ao longo do processo de socialização com o grupo étnico, de modo que o estranhamento em relação ao étnico é similar ao que um não descendente também experimentaria. Assim, a percepção de que "quem está de fora pode estranhar a situação" aparece em várias situações, tais como: "na época que eu ia, eu achava: 'que legal, os japoneses dominam [o Shopping]!' Mas é meio bobo, assim... [para] quem vê de fora e não é descendente...".

Aqui vemos que é sempre aquela relação entre "os de dentro" e "os de fora", no sentido de uma espécie de constante auto-policiamento do tipo: "o que os brasileiros não descendentes devem pensar disso?". Assim como ele, Vinícius, que um dia foi "de fora" do grupo, também, naquela época, nutria uma sensação de estranhamento. Continuando esse raciocínio, ele afirma: "a gente criou uma gíria para esse pessoal; acho que ninguém usa, só a gente: é 'tampa'. Pessoal tapado que vai para o Santa [refere-se ao Shopping Santa Cruz] é tampa”.

O principal motivo aparente que leva à criação dessa gíria que é dirigida ao grupo étnico - e que reforça os seus estereótipos, mantidos, aliás, pelo próprio grupo - é que ela relaciona o fato de o indivíduo querer "ser muito de colônia" (e se ajustar ao estereótipo do "japonês de colônia") com uma presumível falta de personalidade: "talvez eu quisesse ter uma Jansport ${ }^{8}$, mas nunca tive, eu já tinha a minha [mochila] e não ia comprar uma só para querer ser igual aos outros. Parecia que quem era muito de colônia, assim, não tinha muita personalidade: tudo se veste igual. Para quê?".

É interessante notar como os grupos internos ao grupo étnico vão se criticando, criando novos estereótipos internos. Não existe uma homogeneidade interna; existem, sim, vários grupinhos que possuem personalidades diferentes: alguns mais próximos do estereótipo do "japonês de colônia", outros querendo se diferenciar desse estereótipo.

Marca de mochila muito popular entre jovens nipo-brasileiros. 
De toda forma, a ideia do "japonês típico de colônia" parece construir um tipo mais ou menos definido, pois, de acordo com Vinícius, a visão do "pessoal de colônia" é bem estereotipada: "usam Jansport, cabelo McDonalds, camiseta regata, cabelo pintado, jaqueta chamativa... o pessoal já falava mal desse visual na época: 'grupo de street dance é mais colônia; os caras que dançam eram os top top [conhecidos, e os quais as meninas gostam]".

Podemos ver, portanto, que na adolescência os apelos dos agrupamentos étnicos se tornam mais fortes do que na infância, com maiores possibilidades de participação em diversos grupos nos quais os jovens nipobrasileiros vão tendo contato, construindo assim, suas ideias e referências de etnicidade.

\section{EVOLUÇÃO ETÁRIA NO MODO DE PARTICIPAÇÃO NA COMUNIDA- DE: EXPLORANDO DIFERENTES AGRUPAMENTOS/ INSTITUIÇÕES ÉTNICAS}

Como vimos anteriormente, de alguma forma a questão etária se mostrou significativa no modo como os jovens nipo-brasileiros se relacionam com a comunidade nipo-brasileira, e no modo como suas identidades étnicas foram construídas. Nesse sentido, passaremos a análise do modo como os jovens nipo-brasileiros tendem a explorar diferentes associações e agrupamentos étnicos durante certos períodos de tempo, de acordo com a idade e o interesse nesses agrupamentos.

Vinícius, que começou a ter seus contatos com a comunidade nipobrasileira ainda na infância, enquanto frequentava o kaikan próximo ao bairro de onde morava, por influência dos avós, passa na adolescência a se interessar pelo grupo de atletismo de um kaikan da Zona Sul, e por muito tempo permanece nesse grupo até que, em um determinado dia, mudaram o lugar de treino do kaikan o qual ele frequentava, fazendo com que tivesse que se deslocar para a Zona Norte a fim de continuar seus treinos. De acordo com Vinícius, "fomos expulsos [do lugar onde treinavam, que era um ginásio perto do kaikan da Zona Sul] e tivemos que ir para a Zona Norte, mas depois do treino ninguém quer ir pro kaikan [da Zona Sul] pra se encontrar". Por fim, diz ele, "o pessoal que era meus amigos no kaikan já saiu, não está mais lá".

Assim como ele conheceu esse grupo de atletismo nipo-brasileiro na época do colegial, no final do colegial conheceu também outros grupos de nipo-brasileiros por meio do colégio que frequentava. Assim, nessa mesma época, passa a ir a baladas étnicas (tendo como principal público alvo os 
nipo-brasileiros), nas quais, apesar da maioria das pessoas serem nipobrasileiros, não chega a ser um evento exclusivo e fechado (assim como a maioria dos eventos voltados aos nipo-brasileiros não o é). Mas é evidente que a presença de não descendentes de japoneses é muito pequena.

O circuito étnico vai se formando: grupo de atletismo, colégio federal, balada, Shopping Santa Cruz, etc. Uma coisa vai levando a outra, de modo que o jovem vai cada vez mais conhecendo e explorando as diversas instituições, associações, eventos e agrupamentos étnicos. Apesar disso, a capacidade de participar de tantos agrupamentos étnicos ocorre muito devido a questões relacionadas à idade, $\mathrm{o}$ interesse por certas atividades nessa época da vida, a disponibilidade proporcionada pelo fato de só serem estudantes e terem algum tempo livre etc.

O tempo que Vinícius tem que disponibilizar para participar ativamente de agrupamentos étnicos é relativamente grande. No kaikan que fica próximo ao bairro onde morava, por exemplo, ele tinha que ajudar na organização e execução de vários eventos, como por exemplo, as festas do crepe, festa do sorvete, feijoada, do yakissoba, entre outros.

Aqui é necessário enfatizar que dentro de um kaikan existem diversos departamentos, pode ter o departamento dos jovens (seinenkai), das senhoras (fujinkai), do pessoal da terceira idade, do pessoal do atletismo, de grupo de escoteiro, de algum grupo de música, de dança, de arte etc. Cada departamento tende a realizar alguns eventos principais anualmente, e o dinheiro arrecadado por esses eventos são fundamentais no orçamento e manutenção de um kaikan. Além disso, existem eventos que congregam todos os departamentos, um deles ocorre anualmente e é voltado para todo o bairro ocorrendo fora da propriedade do kaikan, incluindo a participação dos não descendentes (tendo parceria com os comerciantes locais), visto que nos demais eventos que normalmente ocorrem dentro do prédio desse kaikan normalmente só vão mais famílias de nipo-brasileiros.

No caso de Vinícius, mesmo que algumas das festas do kaikan não fossem relacionadas ao grupo de atletismo do qual participava, ainda assim ele era chamado a ajudar nessas festas. Embora o seu grupo nada tivesse a ver com esses eventos, lhe era pedido que seus membros ajudassem como garçons para servir as pessoas (assim como os membros de outros departamentos podiam ajudar nos eventos de seu próprio departamento).

De modo geral, podemos afirmar que esses circuitos, associações e agrupamentos são evidências que mostram a força que a etnia ainda apresenta até hoje. De acordo com os dados do Instituto Datafolha (2008) sobre os nipo-brasileiros: 


\begin{abstract}
Um terço (30\%) declara frequentar ou pertencer a alguma associação de cultura japonesa. Entre os que nasceram no Japão, a taxa dos que dizem fazer parte de alguma associação chega a $40 \%$. Entre filhos e netos ela é de $29 \%$. Metade (50\%) dos que foram ao Japão para estudar tem vínculo com alguma associação; entre os que viajaram a turismo essa taxa é de $44 \%$ e entre os que foram trabalhar, de $24 \%$. Os budistas também ficam acima da média nesse aspecto, chegando a 39\% a taxa dos adeptos dessa religião que dizem frequentar alguma associação cultural japonesa. No que diz respeito à idade, os mais jovens são os mais ativos: $37 \%$ dos que têm entre 16 e 24 anos de idade pertencem a alguma associação de cultura japonesa. Entre os que têm de 35 a 44 anos de idade essa taxa cai para 18\%; nas demais faixas etárias ela fica dentro da média (grifos nossos).
\end{abstract}

Assim, ainda existe demanda por associações nipo-brasileiras, apesar da tendência de fechamento de muitas das associações de bairro em muitos locais onde há grande concentração de nipo-brasileiros. Em muitas dessas associações, há um esvaziamento dos jovens, seja devido a influencia do movimento decasségui ${ }^{9}$, seja devido à falta de interesse das novas gerações (pois é uma minoria que participa ativamente de associações).

É necessário enfatizar que o caso de Vinícius é bem específico, uma vez que ele possui grande interesse pela comunidade e, de acordo com suas próprias palavras: "eu sou meio 'quero ser japa', tanto que eu estudo língua japonesa até hoje (...) eu quero prestar a prova Monbusho [bolsa de estudos oferecida pelo governo japonês] para o Japão (...) fiquei sabendo da bolsa no colegial... prestei quatro vezes [a prova] até chegar ao limite da idade". Vinícius também é professor de língua japonesa.

Como podemos ver seu perfil não é tão representativo dos jovens, uma vez que poucos falam a língua japonesa ou se interessam pela cultura e sociedade japonesa. Apesar de apresentar um interesse maior pelos assuntos relacionados à comunidade nipo-brasileira, seu caso é interessante por mostrar como ele vai explorando diversas instituições étnicas ao longo de sua trajetória.

Depois de terminar o colegial, no cursinho ele tem contato com novos nipo-brasileiros, sendo que uma jovem amiga o apresenta para um novo agrupamento, intitulado "Movimento Jovem", que faz parte do Nippon Country Club (localizado em Arujá), conhecido como "o maior clube nikkei das Américas", de acordo com informações de seu site oficial ${ }^{10}$.

\footnotetext{
Termo relacionado ao movimento migratório dos nipo-brasileiros para o Japão em busca de trabalho não qualificado.

0 http://www.nipponclub.com.br/materias.php?cd_secao=7\&codant=\&friurl=:-O-Nippon-Country-Club-:. Site acessado em 09/11.
} 
Vinicius afirma que era sócio desde criança desse clube, mas que raramente o frequentava, e apesar de já ter ouvido falar do Movimento Jovem através do jornalzinho do clube que recebia por ser sócio, só foi conhecer e participar desse movimento através da tal amiga, que era da comissão do Movimento e que o convidou. De acordo com ele: "esse Movimento foi muito bom... eles dão vários ensinamentos, e você faz vários amigos do Brasil todo, vem nikkei do Paraguai, Argentina México e [conheceu um] nihonjin ${ }^{11}$ do Japão [que veio por meio de intercâmbio da Unicamp]".

Vinícius participou do Movimento por dois anos e logo depois acabou conhecendo e frequentando outra instituição, a Abeuni (Aliança Beneficente Universitária de São Paulo). Percebe-se, na fala desse informante, uma miríade de instituições étnicas de descendentes de japoneses espalhadas pela cidade, o que demonstra a força das associações étnicas persistindo nas gerações mais novas. Convém voltar-se um pouco para algumas delas.

Sobre o Movimento Jovem:

O Movimento Jovem Brasil foi criado pelo jovem Cláudio Sassaki em 1997, com base no Líder Câmbio do Peru, sediado no Clube AELU, em Lima. Este, tendo como principais objetivos conscientizar os jovens sobre o seu papel na sociedade através de palestras sobre valores, família, ética, objetivos, pró-atividade e demais qualidades que servem como base para sua formação como agente ativo e benéfico à sociedade. Com base nestas ideias e a vontade de trazer algo que possa acrescentar mais conhecimentos aos jovens do Brasil, Cláudio Sassaki criou o que hoje conhecemos como Movimento Jovem Brasil, ou apenas "Movi”, que, apesar da saída de seu criador, continua ativo e com jovens que foram influenciados por suas palavras e ideais e querem continuar passando isso a outros jovens. $E$ também, através da influência do Movimento Jovem Brasil, foram "plantadas outras sementes", como o "Vibra Jovem" no México, o "Unión Joven Nikkei” do Paraguai, e o "Dale" na Argentina. E no Brasil, temos também o "QuebraCabeça”, evento de integração e conscientização jovem do Rio de Janeiro, e o "Iconikkei” de Brasília. Todos esses eventos são realizados por jovens que um dia participaram do Movimento Jovem Brasil e resolveram passar adiante o que aprenderam a outros jovens ${ }^{12}$. (grifos nossos)

Nihonjin termo referente aos nascidos no Japão.

2 http://www.nipponclub.com.br/lermais_materias.php?cd_materias=126 Site acessado em 09/11. 
Sobre a Abeuni:

ABEUNI é uma entidade filantrópica, sem fins lucrativos, composta por universitários e formados em diferentes áreas.

É também um órgão de utilidade pública, reconhecido pela Assembléia Legislativa de São Paulo (Lei Estadual 9.135/95), pelos trabalhos realizados em prol da sociedade.

A ABEUNI é formada por jovens voluntários que desenvolvem não só o trabalho social assistencial, mas também o lado pessoal, como o trabalho em equipe, liderança e a organização e ainda promove a troca de ideias, experiências e a amizade.

$\mathrm{Na}$ Abeuni (que não é composta somente por descendentes de japoneses, apesar de esses serem a maioria), Vinícius virou chefe do departamento de profilaxia física (cuida de criança até 12 anos), de modo que, até o momento da entrevista, essa era a instituição na qual ele mais atuava. Sobre as razões para ter saído do Movimento Jovem e se interessado mais pela Abeuni, ele afirma:

No Movimente a gente aprende vários valores pessoais né? [valores] que a gente aplica na nossa vida. "Para construir um mundo melhor", esse é o lema, só que aí se fica só nisso, você não está agindo, você só está aprendendo, e na Abeuni a gente põe em ação. Tem uma menina que eu conheço da Abeuni que também veio do Movi, e falou: 'é não adianta só ficarem lá, e não pôr em prática, na Abeuni a gente põe em prática porque é um trabalho voluntário’. (grifos nossos)

Vinícius afirma também haver uma divisão interna por faixa etária dentro do Movimento Jovem: o "Mobilize-se" é para os acima de 18 anos; o Movimente é para os de 14 anos para cima. "Eu, quando fui com 19, me chamavam de velho", diz ele.

VOLUNTARISMO ÉTNICO: COMO MANTER AS ASSOCIAÇÕES ÉTNICAS ENTRE AS GERAÇÕES MAIS NOVAS?

Como vimos anteriormente parece haver alguma relação entre o interesse por grupos étnicos relacionados à questão da faixa etária e do modo de socialização. Assim, nesses casos, o indivíduo tende a permanecer nos grupos étnicos enquanto dure seu interesse pela socialização com membros da mesma etnia, ou enquanto encontra dentro da comunidade um nicho 
voltado a atividades relacionadas a certas faixas etárias. É claro que não são somente esses aspectos que influenciam no interesse dos jovens nipobrasileiros em participar de grupos étnicos; porém, nos limites deste trabalho, somente esses recortes foram possíveis de serem observados.

Nos relatos acima foi interessante observar como a "comunidade" é descoberta pelos jovens descendentes de japoneses e como ela é explorada por eles, ficando evidente a força que os grupos étnicos nipo-brasileiros ainda possuem em moldar a identidade de muitos jovens, sendo uma forma de socialização muito forte, principalmente no período da adolescência. Mas o que acontece depois dessa fase? Será que na vida adulta, quando há menos tempo disponível para participar de grupos étnicos, esses jovens ainda se interessarão pelas associações nipo-brasileiras?

Ainda que, em exemplos individuais, a socialização e laços de amizade entre membros do grupo étnico possam persistir a vida inteira, o que questionamos é como, coletivamente falando, se pretende manter as associações nipo-brasileiras sempre ativas e atraindo novos membros. Como vimos acima, a frequência a uma associação nipo-brasileira não é regular durante todas as fases da vida, sendo mais comum haver idosos ativos, mais do que jovens, que permaneçam nela por muito tempo, mesmo porque, passando a fase da adolescência e da faculdade, muitos jovens se veem na situação de ter outros compromissos mais importantes do que a participação em associações étnicas. De acordo com Gans (1979: 8):

Dado o grau no qual a terceira geração tem se aculturado e assimilado, a maioria
das pessoas procuram por maneiras fáceis e intermitentes de expressarem suas
identidades, por maneiras que não conflitam com outros modos de vida. Como
resultado eles se abstêm do comportamento étnico que requer um comprometimen-
to árduo e consumidor de tempo, seja para uma cultura que deve ser praticada
constantemente, ou para uma organização que demanda uma associação ativa
(tradução nossa).

É comum ouvir relatos de "abandono" dos locais de socialização nipo-brasileiros logo após saírem da adolescência e encararem a faculdade e outras tarefas que tomam o tempo dos jovens atualmente. Os próprios entrevistados assumem que, depois de certo tempo de convívio social e participação em atividades relacionadas à comunidade nipo-brasileira, chega um momento em que "os grupos se desfazem" e eles começam a ter outros tipos de atividades e tarefas, deixando de lado os esportes, as festividades, as associações etc. 
Assim, o interesse pela comunidade, que já é pequeno entre os descendentes de japoneses, torna-se mais escasso e suas aparições nos eventos da comunidade, mais esparsos. Como então as associações se mantêm, para além da época da adolescência e passagem para a vida adulta? É plausível pensar que esses jovens um dia também levarão seus filhos para associações e que estes repetirão rituais parecidos de socialização dentro da comunidade? Apesar de estar fora do escopo dessa pesquisa dar respostas a todas essas perguntas, podemos fazer um exercício de reflexão sobre como manter esse laço com a comunidade étnica de forma mais permanente e duradora ao longo da vida, tendo em vista a importância desses laços para a manutenção da comunidade.

Nesse ponto, é interessante o relato dos jovens frequentadores de um kenjinkai ${ }^{13}$, localizado na zona sul de São Paulo. Esse kenjinkai é conhecido por conseguir manter um grupo de jovens frequentando de modo menos fugaz a associação, servindo de exemplo às outras associações, visto que é bem conhecido o relato sobre a dificuldade em se conseguir atingir o nível de um grupo jovem, unido e estável ao longo do tempo que seja atuante nas atividades que a associação promove. $\mathrm{O}$ mais comum é que acaba chegando um momento em que os jovens vão perdendo o interesse, os grupos vão se espalhando, as pessoas vão tendo outras atividades e os antigos grupos desaparecem.

O caso de Paulo é interessante: em sua infância, chegou a participar de um kaikan, mas parou de frequentar quando entrou no colegial, só voltando a participar de alguma associação étnica aos 30 anos, quando recebeu o convite de pessoas que participavam do kenjinkai do qual faz parte atualmente. Segundo Paulo, ele é o único da família que participa (entre pais, avós e irmãs), e afirma: "eu acho que é a nova tendência hoje você não participar com a família, isso já acabou, eu acho, não tem mais nessa geração", ou seja, a participação é mais individual ou, no máximo, inclui cônjuges e filhos, mas não é mais algo que agrega toda a família, de maneira ampla, como antigamente.

Sobre a falta de renovação por parte de muitas associações nipobrasileiras, ele diz:

\footnotetext{
Kenjinkai, assim como o kaikan, é um tipo de associação de caráter cultural e esportivo que agrega pessoas interessadas na cultura japonesa em geral, porém cada associação possui um vínculo com uma província específica do Japão.

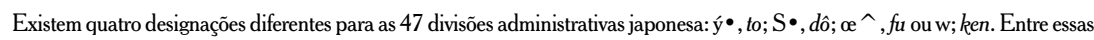
divisões administrativas, 43 usam o termo ken, de kenjinkai; as demais, portanto, não seriam chamadas de kenjinkai. 
As associações não enxergaram como atrair o jovem e procuram manter um sistema até antigo de rigidez japonesa ou alguma coisa nesse sentido. Eles perderam o bonde, então as pessoas se afastaram, então o clube vive com os velhos que estão vivos nascidos naquela província, no caso kenjinkai, ou nos casos dos clubes de bairros, as velhinhas e as senhoras. Mas conforme o tempo vai passando, a coisa vai ficando mais decadente né? Então atrai menos os jovens.

Sobre o comprometimento dos jovens com esse kenjinkai:

Tudo começa com duas ou três pessoas que pensam em alguma coisa, "vamos fazer", assumem aquele desafio, e as pessoas que estão em volta delas ajudam e vêm atrás. Agora, existe essa liderança que puxa, que na verdade se você vai a algum lugar que não tem ninguém que puxa, a pessoa fala: "ah, eu não vou lá porque não tem nada, mas se tivesse eu iria”. Aí vai, aparece, aí começa a ir, quando você vai lá você já encontra amigos, faz novas amizades, esse ambiente saudável que vai somando e vai vindo, mas quando essa liderança para de chamar, ela também pulveriza. Por quê? Porque essas pessoas que vêm, elas arrumam outras atividades em outros grupos né? Então elas... A sociedade já não é dependente do kenjinkai, é o contrário, o kenjinkai é que depende das pessoas. Então hoje mudou, antigamente o kaicho [presidente] do kenjinkai era um líder de comunidade, hoje ele não é, na verdade, ele é uma pessoa que vai ter que atrair a comunidade porque a comunidade virou as costas para os kaikans, ele [essa pessoa] não vem naturalmente, ele vem se tiver algum motivo. (grifos nossos)

Assim, se nas origens da sua formação, os kenjinkai, estavam relacionados às questões do Pós-Segunda Guerra Mundial, e tiveram um papel essencial de ligação entre a sociedade japonesa e os imigrantes e descendentes no Brasil oriundos das 47 províncias do Japão, atualmente não está mais tão claro qual o papel que essas associações específicas de província japonesa possuem ou possuirão no futuro. De acordo com Paulo:

O Japão participa cada vez menos, eu diria que hoje no Brasil. Metade das associações kenjinkai no Brasil já não tem mais dinheiro de contribuinte de imposto de governo japonês. Eles mandaram dinheiro para construir, e eles mandam dinheiro anualmente. Eu não tenho certeza do valor, mas deve ser alguma coisa entre $\mathrm{R} \$ 4.000$ e $\mathrm{R} \$ 5.000$, é muito por ano, é simbólico, mas eles continuam mandando. Existia dentro da mentalidade, do imaginário, assim como existe ainda hoje, uma idéia de que as pessoas que saíram daquela província, eles estão tão longe, no Brasil, eles estão tão longe da terra natal que seria importante manter um 
escritório lá para acolher essas pessoas, que é o surgimento de todos kenjinkai. É em função disso, da convivência de uma comunidade japonesa fora do Japão, e eles entendem, na mentalidade, no imaginário japonês, que eles contribuíram para a construção, e [por isso] eles contribuem anualmente em função dos nascidos na província de origem.

De modo geral, o relacionamento Brasil-Japão nos últimos tempos tem ocorrido muito em torno do movimento migratório dos nipo-brasileiros para o Japão. A relação atual, portanto, não é tão forte quanto já foi antigamente. Uma prova do desinteresse japonês pela comunidade nipo-brasileira foi que o Centenário da Imigração Japonesa ao Brasil só foi verdadeiramente comemorado no Brasil, abraçado amplamente por toda população brasileira, incluindo aí os não descendentes de japoneses, e recebendo larga atenção da mídia durante longo período de tempo. Ao contrário do Brasil, quase não houve repercussão ou interesse pela sociedade japonesa em geral.

Uma pesquisa encomendada pelo governo japonês em 2008, feita em fevereiro desse mesmo ano, nas vésperas das comemorações do Centenário, mostrou que os japoneses desconhecem o Brasil. De acordo com o Masuo Nishibayashi (cônsul-geral do Consulado do Japão em São Paulo): "a pesquisa foi feita por causa do Centenário da Imigração. $\mathrm{O}$ intuito era saber qual a opinião dos japoneses em relação ao Brasil. $\mathrm{O}$ resultado, infelizmente, mostra que eles conhecem pouco" (Jornal Nippo-Brasil, 2008, p. 4A).

Sobre a pesquisa:

\footnotetext{
O item que abordava a familiaridade dos japoneses com o Brasil mostrou que 41\% dos entrevistados não têm nenhuma familiaridade com o país, enquanto $23 \%$ disseram ter alguma familiaridade com o país. Com relação à opinião sobre a relação nipo-brasileira, $57,8 \%$ não teve um parecer sobre o assunto e apenas $30 \%$ disseram que a relação é boa. No item que indagava sobre a parceria entre os dois países, 31,4\% dos entrevistados não souberam responder e 50\% disseram que é uma relação boa.

No item que avaliava a colaboração dos brasileiros ao Japão, 32,4\% dos entrevistados disseram acreditar que os brasileiros contribuem com o país e $32,8 \%$ acharam a presença brasileira indiferente; $21,4 \%$ dos entrevistados não souberam responder (Ibid.: 4A).
} 
Como podemos ver, se o interesse japonês pelo Brasil é pequeno, assim como as associações de província já não possuem mais um objetivo claro dentro da comunidade nipo-brasileira, é compreensível que as jovens lideranças repensem a atuação do kenjinkai.

Sobre o interesse dos japoneses em manter e apoiar os kenjinkais, Paulo afirma que:

Está se vendendo um peixe agora... Durante muito tempo né? Na verdade, é que agora existe um resgate à terra dos antepassados, só que mais do que isso, existe novamente um interesse comercial que poderia surgir a partir dessa relação, então talvez assim, o futuro de uma associação como o kenjinkai, ou como de qualquer outra, é você ter uma divulgação da cultura desse kenjinkai e do interesse turístico na província de origem, um interesse econômico da província aqui no Brasil. Então, fazer o japonês [do Japão] se interessar em manter uma associação lá no Brasil, porque ele tem um interesse no brasileiro e no Brasil, e não mais no japonês que foi para lá; então, esse ponto de vista é viável né? e se tornou mais viável ainda agora que o Brasil está se destacando.

Dentro do contexto em que cada vez menos descendentes de japoneses se interessam pela língua ou cultura japonesa, o futuro da comunidade étnica passa então a estar nas mãos, cada vez mais, dos não descendentes. Sobre o assunto, Paulo afirma:

\footnotetext{
Meu sonho era que o kenjinkai fosse frequentado por $90 \%$ de não descendentes de japoneses, mas que todos gostassem da cultura da província original do kenjinkai, ou da cultura japonesa aqui no Brasil. E, então, [que] aqui fosse um centro cultural de cultura japonesa e [da] cultura da província do qual o kenjinkai faz parte, e não um clube exclusivamente feito por descendentes que vieram dessa província. [as reações dos issei e nissei foram] "só por cima do meu cadáver"; “enquanto eu estiver vivo não”, etc. Eu falei: "então espera mais um pouquinho, porque vai morrer daqui há pouco vocês, não é? então quando vocês morrerem e não estiverem mais aqui..." eu não falei isso, pensei né? Mas assim: "quando vocês não estiverem mais aqui...”.
}

Aparentemente, a antiga geração ainda resiste à mistura com os não descendentes. E a nova geração pretende uma espécie de modernização da figura e atuação das associações nipo-brasileiras, adequando-as aos novos modelos globalizados: turismo, comércio, cultura. 
Sobre o esforço do kenjinkai e seu impacto na comunidade étnica, Paulo afirma:

[Nosso kenjinkai], especificamente, ele tem uma sorte, uma característica na verdade, ele tem muitos jovens, comparado com os outros kenjinkais, então ele é muito elogiado dentro da comunidade kenjinkai, [...] as pessoas não entendem porque a gente tem jovens e jovens comprometidos, jovens ativos que fazem a coisa acontecer e mantêm a tradição de festas, [...] mas é um movimento pequeno, é uma gota d'água, é num clube pequeno, na verdade, mas que causa impacto às vezes na comunidade, assim, porque ele aparece, e ele atrai pessoas [...] (grifos nossos).

Como foi dito acima, essas tentativas de manter a associação ativa e funcionando "é uma gota d'água" dentro do universo maior que abrange os nipo-brasileiros no Brasil.

De modo geral, podemos afirmar que a cultura nipo-brasileira já faz parte da sociedade brasileira, já entrou para o calendário de eventos da cidade de São Paulo. Um exemplo disso foram as comemorações em torno do Centenário da Imigração Japonesa no Brasil, em 2008, que só vieram a fortificar o sentimento entre os brasileiros de que a cultura nipo-brasileira também os pertence.

A relação entre associações étnicas e a população brasileira de não descendentes de japoneses tem crescido, sendo também essa uma tendência para as associações que procurem manterem-se ativas.

Como vimos, a tendência é que haja cada vez mais a participação dos "de fora" dentro da comunidade étnica, ou seja, não é possível pensar a comunidade nipo-brasileira sem se pensar na participação - que atualmente ainda é fraca - da população em geral de não descendentes.

De modo geral, procuramos mostrar alguns dilemas e tensões internos à comunidade; mas apesar disso, pudemos observar também que a comunidade ainda serve como forma de integração e socialização, e possui ainda um peso relativamente grande como referência de identidade étnica, comportamento, valores, tradições etc.

\section{CONSIDERAÇÕES FINAIS: PROXIMIDADE E DISTÂNCIA DA ETNICIDADE E DE ASSOCIAÇÕES ÉTNICAS.}

Como pudemos ver, o modo como os jovens tendem a compreender a etnicidade ocorre muito por meio da proximidade ou distancia de associa- 
ções ou agrupamentos étnicos, daí as expressões do tipo: "descobri a comunidade", ou "o mais próximo que cheguei da comunidade" etc.

Para os olhares da população externa de não descendentes de japoneses, essa é uma questão quase imperceptível, visto que a maioria desconhece essas variações internas. Pelo contrário, aos olhos de quem está de fora, a comunidade aparenta ainda ser relativamente forte e coesa, devido não só a todo aparato comunitário, como também ao fato de ainda existirem agrupamentos étnicos, principalmente grupos de jovens, como pudemos observar.

Também pudemos observar, por outro lado, que, nos últimos tempos, ainda há variados modos de participar da comunidade, mesmo que seja apenas em um período da vida, em especial na adolescência.

Assim, enquanto houver aparatos comunitários, associações ativas e voluntários jovens que deem continuidade a todo esse aparato, a percepção da existência de uma relativamente forte e visível comunidade nipo-brasileira (marcada por essas instituições espalhadas por toda cidade de São Paulo) irá persistir.

Como pudemos observar essa rede étnica ainda é relativamente ativa entre os jovens nipo-brasileiros. Porém, mesmo aqueles voluntários que participam largamente da manutenção e construção das associações nipo-brasileiras preveem que estas no futuro talvez sejam mais voltadas ao contato direto com o Japão, ou seja, servirão como divulgador do Japão, da cultura e do aspecto turístico, mais do que locais que procurem preservar a cultura "tradicional e antiga" japonesa trazida pelos imigrantes no século passado. Além disso, essas associações terão maior participação da população brasileira não descendente de japoneses (pelo menos essa é a tendência, visto que para sobreviver, as associações não podem só contar com a população de descendentes de japoneses no Brasil).

Esse ponto é interessante, pois pudemos constatar que a comunidade nipo-brasileira (em termos de associações e agrupamentos étnicos) não necessariamente tem a ver com algum tipo de relação direta com Japão, nem consideramos a participação dos não descendentes de japoneses na comunidade (mesmo porque, ainda são muito poucos). De modo geral, existem várias formas de se experimentar a etnicidade, porém, no escopo deste artigo, procuramos limitar a análise da etnicidade a apenas alguns agrupamentos e associações étnicas. 


\section{REFERÊNCIAS BIBLIOGRÁFICAS}

CARDOSO, Ruth C. L. Estrutura familiar e mobilidade social: estudo dos japoneses no Estado de São Paulo. São Paulo: Kaleidos- Primus Consultoria e Comunicação Integrada S/C Ltda, 1998.

CARDOSO, Ruth C. L. "O Papel das Associações Juvenis na Aculturação dos Japoneses". In: Revista de Antropologia, vol. 7, 1959.

FUGITA, Stephen; O'BRIEN, David, J. Japanese American ethnicity: the persistence of community. Seatle; London: University of Washington Press, 1991.

GANS, Herbert J. "Symbolic ethnicity: The future of ethnic groups and cultures in America". Ethnic and Racial Studies, 2:1, 1-20, 1979.

DATAFOLHA. Centenário da Imigração japonesa, 2008. Disponível em: http://datafolha.folha.uol.com.br/ po/ver_po.php? session=794 Acessado em: 08/2010.

SEYFERTH, Giralda. "Imigração e (re)construção de identidades étnicas". In: Cruzando fronteiras disciplinares: um panorama dos estudos migratórios. Neto, H; Ferreira, A. (orgs.). Rio de Janeiro: Editora Revan, 2005. 